1994-1

\title{
The Multidimensional Assessment of Career Decision Problems: The Career Decision Diagnostic Assessment
}

Jeffry H. Larson

Brigham Young University - Provo

Dean M. Busby

Brigham Young University - Provo, dean_busby@byu.edu

Stephan Wilson

University of Kentucky

Nilufer Medora

California State University, Long Beach

Scot Allgood

Etolbutthis and/andditional works at: https://scholarsarchive.byu.edu/facpub

Part of the Other Social and Behavioral Sciences Commons

\section{Original Publication Citation}

Larson, J. F., Busby, D. M., Wilson, S., Medora, N., \& Allgood, S. A. (1994). The multidimensional assessment of career decision problems: The career decision diagnostic assessment. Journal of Counseling and Development, 72, 323-329.

\section{BYU ScholarsArchive Citation}

Larson, Jeffry H.; Busby, Dean M.; Wilson, Stephan; Medora, Nilufer; and Allgood, Scot, "The Multidimensional Assessment of Career Decision Problems: The Career Decision Diagnostic Assessment" (1994). Faculty Publications. 4587.

https://scholarsarchive.byu.edu/facpub/4587

This Peer-Reviewed Article is brought to you for free and open access by BYU ScholarsArchive. It has been accepted for inclusion in Faculty Publications by an authorized administrator of BYU ScholarsArchive. For more information, please contact ellen_amatangelo@byu.edu. 


\title{
The Multidimensional Assessment of Career Decision Problems: The Career Decision Diagnostic Assessment
}

\author{
Jeffry H. Larson, Dean M. Busby, Stephan Wilson, Nilufer Medora, and Scot Allgood
}

\begin{abstract}
The multidimensional assessment of career decision problems as measured by the Career Decision Diagnostic Assessment (CDDA; Bansberg \& Sklare, 1986) is described, and the CDDA is evaluated for reliability, validity, and factor structure with a sample of 844 students from three universities. Results supported the reliability and validity of the CDDA as a measure of psychological blocks to career decision making. Preliminary normative scores for university students are presented. Recommendations for improving the CDDA and for using the CDDA in career counseling are discussed.
\end{abstract}

$\mathrm{C}$ areer counselors frequently encounter individuals who seem unable to make a career decision. "Even though the counselor may have done his/her best to assist by providing them with career information, interest inventories, and ability assessments, etc., they still are not closer to a career decision"' (Bansberg \& Sklare, 1986, p. 1). These students are difficult and frustrating to counsel.

The traditional method of career counseling has typically approached a career decision problem as a need for self- or occupational information. There are many quality career counseling instruments available to assist individuals with learning more about their interests, work values, abilities, and career alternatives. These include interest inventories, ability assessments, computerized career guidance systems, and so forth.

Recent research in career decision making, however, strongly suggests that there is more involved in career decision making than obtaining information (Bansberg \& Sklare, 1986; Crites, 1981; Holland \& Holland, 1977; Osipow, 1983). There seem to be various intrapersonal motivations or problems that can interfere with career decision making. These include anxiety, an external locus of control, lack of self awareness, and other "personality problems" (Bansberg \& Sklare, 1985; Crites, 1981; Hartman, Fuqua, \& Blum, 1985).

Although the reliable and valid assessment of career decision problems as personality problems is now an important issue in the field of career counseling (Kapes \& Mastie, 1988; Slaney, 1988a), there currently are only a few frequently used instruments available to career counselors that seem to have adequate support regarding validity and reliability (Slaney, 1988a). The purpose of this study was to (a) introduce a relatively new instrument, the Career Decision Diagnostic Assessment (CDDA; Bansberg \& Sklare, 1986); (b) describe a study of the psychometric properties-reliability and validity-of the CDDA; and (c) make recommendations about its usefulness in career counseling based on the findings.

"The CDDA was developed exclusively to address the issue of identifying the most common deflections (psychological blocks) to career decision making"' (Bansberg \& Sklare, 1986, p. 1). Its alleged purpose is to allow the career counselor to identify both the type(s) and degree of psychological blocks to career decision making (Bansberg \& Sklare, 1986).

Psychological blocks may be affective, cognitive, or behavioral (Bansberg \& Sklare, 1986). Decision anxiety is an affective psychological block that inhibits career decision making (Hartman et al., 1985) by immobilizing the individual (Blum, 1985). Anxiety may be due to unrealistic expectations, fear of success or failure, fear of change, or intermodal conflicts experienced when an individual possesses two strong but opposite vocational personality traits (e.g., creativity and conventionality) (Holland \& Holland, 1977). In contrast, a lack of life/goal awareness may be categorized as a cognitive psychological block to career decision making (Bansberg \& Sklare, 1986). It may be due to unresolved identity issues, a lack of purpose, mission or goals, or an unawareness of needs (Bansberg \& Sklare; Hartman et al., 1985).

Authority orientation and a luck-and-fate orientation to career decision making reflect both cognitive and behavioral blocks. Individuals with these blocks tend to accept uncritically the values and beliefs of others (often a parent or significant other), have low self-esteem, and avoid responsibility in career decision making (Bansberg \& Sklare, 1986). Secondary gain motivation is another psychological block to career decision making that could best be described as cognitive and behavioral (Bansberg \& Sklare). Here the individual is motivated not to choose a career because of perceived disadvantages, such as "If I choose a career in art instead of medicine, my parents will never forgive me.", Thus, the best perceived alternative may be not to make a choice. Other individuals may be nonconformists or may be manipulating the system to avoid employment and still receive compensation.

The CDDA's potential value to the career counselor is that it claims to identify those individuals who need more than occupational interest and ability information to make an appropriate career decision. The CDDA is intended to be administered to individuals in conjunction with standard career assessment tools such as interest inventories, ability measures, and personality tests (Bansberg \& Sklare, 1986).

The CDDA is a self-report, written instrument consisting of 37 items. The first item asks individuals if they have made a specific decision about a career choice or change. The second item asks them how certain they are in their choice of a career. Items 3 to 36 consist of statements about career decision making, to which participants indicate their degree of agreement or disagreement on a 6-point scale ( $1=$ strongly agree to $6=$ strongly disagree). The higher the score on the CDDA, the greater the career decision problems. The last item asks if the person has answered each of the items honestly. The test takes approximately 15 to 20 minutes to complete. It may be administered individually or in groups.

The CDDA provides the career counselor with a total career decision problems score (range, 36 to 180) and five subscale scores (Bansberg \& Sklare, 1986). The subscales include the following:

1. Life/goal awareness (LGA; seven items). This is the degree of knowledge, understanding, and insight that an individual possesses in 
regard to what it is that he or she wants and needs out of life (e.g., "I can name the three most important things that I need in a career/job to be satisfied"). The concept of life/goal awareness is based on Frankl's (1970) theoretical premise of the drive of will to meaning (Bansberg \& Sklare, 1986).

2. Decision anxiety (DA; nine items). This is the degree of internal struggle or ambiguity an individual experiences regarding the career decision-making process. This internal struggle leaves an individual immobilized in the progression toward career selection (e.g., "There is one part of me that wants to commit myself to a career/job choice"). This concept is an extension of the theory of polarization advanced by Perls (1979). The etiology of decision anxiety may originate from a variety of sources, such as fear of failure or success (Esposito, 1977) or approach/avoidance (Dollard \& Miller, 1950).

3. Secondary gain (SG; six items). This is the degree of advantage or gain that an individual receives by not making a commitment to a career decision. The etiology of secondary gain may involve conscious or unconscious motivations (e.g., "I have something to lose by making a career/job choice at this time"). The phenomenon of secondary gain is related to a concept identified by Krumboltz and Thoresen (1976), in which the problem is a vested interest (secondary gain) in not identifying a career goal.

4. Authority orientation (AO; five items). This is the degree of dependence or desire an individual has for an authority figure to make decisions for him or her (e.g., "My parents [or spouse, family, etc.] know better than I what is the best choice for me on important decisions"). Authority orientation emanates from Rotter's (1954) concept of locus of control. Authority orientation blocks career choice through anticipation of input from significant others or through introjection conflicts.

5. Luck and fate orientation (LFO; seven items). This is the degree of belief that an individual has in the existence of luck and fate as the prime determinant in ultimate success or failure in life (external locus of control) (e.g., "I don't think career planning really makes a difference. Ultimately the job I end up with will be the result of luck or opportunity"). Luck-and-fate orientation maintains career indecisiveness through the replacement of personal responsibility with a belief in an inability to personally influence the future (Rotter, 1954). The relationship of locus of control to career decision making has been well documented (Hartman et al., 1985; Taylor, 1982).

Individuals calculate their own subscale and total scores on the CDDA by using the CDDA scoring form. The total CDDA score is calculated by adding the numbers representing responses to the 34 items (i.e., items 3 to 36 ). The ranges of scores for the total and subscale scores are provided on the CDDA scoring form, and individuals can determine if their scores are in the "low range" (no significant problems), in the "middle range"" (some problems), or in the "high range" (significant problems in career decision making exist). The individual's scores and the ranges in which the scores fall are not self-explanatory and must be discussed with a counselor (see the CDDA manual [Bansberg \& Sklare, 1986] for details on the interpretation of scores).

The CDDA holds promise as a new instrument for measuring career decision problems because it provides the counselor with both a general measure of psychological blocks to career decision making (i.e., the total CDDA score) and specific measures of psychological blocks (i.e., the five subscale scores). Oliver (1979) has emphasized the importance of measuring specific underlying dimensions of a career decision problem.

The psychometric characteristics of the CDDA were described by Bansberg and Sklare (1986) in their original development of the CDDA. Conducting research on a sample of 931 high school sophomores through community college students, they reported internal consistency reliability for the total test as alpha $=.94$. The alpha levels for the subtests were as follows: LGA, .82; DA, .88; AO, .76; LFO, .77; and SG, 82 . The correlations between the subscales ranged from .24 to .62 , with the mean $r=.46$.

External validation for the CDDA was provided by comparisons that were done between the CDDA and four other instruments: The Purpose in Life (PIL), My Vocational Situation (MVS), the Adult NowickiStricklin Internal External Scale (ANS-IE), and the Strong-Campbell Interest Inventory (SCII). The PIL, MVS, and the ANS-IE were selected for tests of convergent validity; the SCII was used to help establish discriminant validity (Bansberg \& Sklare, 1986). There was a significant negative correlation $(r=-.62)$ between the CDDA total score and a need for meaning or purpose in life as measured by the PIL. There was a significant negative correlation, $r=-.65$, between career decision problems as measured by the CDDA total score and the MVS scores that measure a lack of vocational identity, limited occupational information, and personal barriers. Locus of control as measured by the ANS-IE was significantly related to the CDDA total score, $r=-.42$, indicating more significant career decision problems for those with an external rather than internal locus of control. External locus of control also was significantly related to LFO, $r=-.36$, and $\mathrm{AO}, r=-.28$, as measured by these CDDA subscales.

Bansberg and Sklare (1986) also computed correlations between the CDDA total score and subscale scores and select scores on the SCII to show evidence of discriminant validity for the CDDA. They found the following: First, a high score on the CDDA correlated significantly, $r=.24$, with a high number of dislikes on the SCII. This was tentatively interpreted to mean that "individuals with psychological blocks to career decision making may not be ready to take an interest inventory and therefore, their interest profiles may not show clear or useful results" (p. 7). Second, high AO scores correlated significantly, $r=-.24$, with low overall general interest themes on the SCII. This was interpreted to mean that individuals with an authority orientation may want others to make choices for them and thus will score low in any area on the SCII. Third, high-dichotomized DA scores were significantly negatively correlated, $r=-.23$, with academic comfort on the SCII. This was interpreted to mean that individuals who lack comfort with academics will also have greater anxiety and struggle with career decision making. Fourth, high CDDA total scores and all subscale scores (except $\mathrm{SG}$ ) correlated significantly ( $r$ s ranged from .26 to .32 ) with introversion on the SCII. Bansberg and Sklare concluded that introverted individuals may have more career decision problems than extroverted individuals but did not provide an explanation.

Evidence for construct validity for the CDDA was generated by using a factor analysis procedure. Bansberg and Sklare (1986) set a maximum of five factors, with an oblique rotation and used a minimum eigenvalue of 1.0. The factor analysis procedure resulted in a five-factor structure for the CDDA corresponding to the subscales of the instrument.

Although no significant differences were found between mean total scores of men and women, men scored significantly higher on two of the subscales-LFO and SG. The authors, however, provided no mean scores, standard deviations, or $t$-test information for the two gender groups nor did they interpret these findings. There were no significant differences between age groups on the CDDA total score or subscale scores. Bansberg and Sklare (1986) interpreted this to mean that age does not affect psychological patterns of career decision making.

The fundamental question of this study was "Are Bansberg and Sklare's (1986) reliability and validity results replicable with a different 
sample?"' The importance of replication with different samples in the assessment of the reliability and validity for career counseling diagnostic instruments has been emphasized by Oliver (1979) and Zytowski and Betz (1972). This study also sought to provide the following new information about the CDDA:

1. Mean scores and standard deviations (preliminary norms) were computed on the CDDA separately for men and women. Research on women's career development has shown that it is a process separate and different from men's career development (Fitzgerald \& Betz, 1983). Career decision problems also may vary by gender as a function of socialization or psychological differences between men and women (Astin, 1984; Fitzgerald \& Betz, 1983; Larson, Butler, Wilson, Medora, \& Allgood, 1991). Mean scores and standard deviations (preliminary norms) were also computed for different class standings using a university sample.

2. Using a university student sample, factor analysis procedures were used to determine if the CDDA would yield the same five subscales that Bansberg and Sklare (1986) found with their sample of high school and community college students.

3. To assess the convergent validity of the CDDA further, we compared students' scores on the CDDA to their scores on the Career Decision Scale (CDS; Osipow, 1980), one of the most widely used measures of career indecision (Slaney, 1988a). A review of the items on the CDS revealed that it may measure some of the same variables as the CDDA (e.g., decision anxiety).

\section{METHOD}

\section{Participants}

The 844 students in this study came from three major universities: Illinois State University $(n=350)$, Brigham Young University $(n=321)$, and California State University, Long Beach $(n=173)$. The sample consisted of $388(45 \%)$ men and $456(55 \%)$ women. The mean age for the students was 19 years (range $=17$ to 23 years). The mean family income was relatively high: $\$ 49,500$. Of the total 844 students, 468 (55\%) were freshmen, 267 (32\%) were sophomores, and $109(13 \%)$ were first-semester juniors. Most of the students were Catholic (24\%), Protestant (36\%), or Latter-Day Saints (36\%). They were largely from urban backgrounds. The sample was mostly White (89\%), but other groups were also represented: Asian Americans (6\%), Hispanics (3\%), and African Americans (2\%).

\section{Instruments}

Students completed a short questionnaire to provide demographic data, the CDDA, and the CDS (Osipow, 1980). Most students completed the questionnaires in psychology or family science classes.

The CDDA has already been described. The CDS is a 19-item, self-report measure of components or antecedents of career indecision (Osipow, 1980). It provides a total score, but not subscale scores. In a review of the statistical properties of the CDS, Slaney (1988) reported test-retest reliabilities of $r=.82$ to .90 . He also reported evidence of construct and concurrent validity for the CDS, but indicated that "the factor structure of the scale needs additional clarification" (Slaney, 1988, p. 173).

\section{RESULTS}

\section{Group Differences}

Table 1 shows the means, standard deviations, and $t$ tests for the CDDA total scale and subscales for university students by gender. Because the CDDA subscale scores were moderately correlated (mean $r=.46$ ), Haase's (1980; Haase \& Ellis, 1987) method of controlling for experimentwise error was used. Haase's method for determining the alpha level is based on the number of dependent variables, the degree of intercorrelation between the dependent variables, and the sample size. No individual effects were considered to be significant unless $p<.01$. The mean scores can be used as preliminary normative scores with which to compare university students. Unfortunately, these scores cannot be directly compared to Bansberg and Sklare's (1986) scores for high school and community college students. Their test manual does not provide mean scores and standard deviations by gender, but instead lists frequencies of ranges of scores (e.g., 53\% of their sample had a total score of 30 to 89 ).

The results in Table 1 show that women scored significantly higher $(M=15.92)$ than did men $(M=14.93)$ on the LGA subscale, $t(d f=843)$ $=-2.82, p<.005$. That is, women reported a greater lack of life/goal awareness than men. The women also scored significantly higher $(M=$ 10.44) than did men $(M=9.67)$ on the AO subscale, $t(d f=843)=-2.94$, $p<.003$. Women had a greater problem with dependence on authority than did men. Women scored significantly lower $(M=15.60)$ than did men $(M=17.70)$ on the SG subscale $t(d f=843)=5.78, p<.0001$. That is, women reported less problem with secondary gain motivations in

TABLE 1

Means and Standard Deviations on the CDDA for Male and Female University Students and $t$ Tests for Sex Differences

\begin{tabular}{lrrrrr}
\hline \hline Subscale & Men & Women & $\boldsymbol{t}$ & df & $\boldsymbol{p}$ \\
\hline Life Goal Awareness & & & & & \\
$M$ & 14.93 & 15.92 & -2.82 & 843 & .005 \\
$S D$ & 4.82 & 5.22 & & & \\
Decision Anxiety & & & & & \\
$M$ & 25.44 & 25.91 & & & \\
$S D$ & 7.62 & 8.40 & -0.82 & 843 & .410 \\
Authority Orientation & & & & & \\
$M$ & 9.67 & 10.44 & & & \\
$S D$ & 3.54 & 4.06 & -2.94 & 843 & .003 \\
Luck/Fate Orientation & & & & & \\
$M$ & 17.24 & 16.58 & & & \\
$S D$ & 5.11 & 5.06 & 1.88 & 843 & .061 \\
Secondary Gain & 17.70 & 15.60 & & & \\
$M$ & 5.25 & 5.22 & 5.78 & 843 & .000 \\
$S D$ & & & & & \\
Total & & & & & \\
$M$ & 84.85 & 84.41 & & & \\
$S D$ & 19.89 & 21.77 & 0.30 & 843 & .765 \\
\hline
\end{tabular}

Note. CDDA = Career Decision Diagnostic Assessment. $n$ (men) $=388$; $n$ (women) $=456$.

The higher the score on each CDDA subscale, the greater the problem. Possible ranges for the subscales are: LGA, 7-42; DA, 9-54; AO, 5-30 LFO, 7-42; SG, 6-36. Possible range for the total score is $36-80$. 
career decision making than did men. There were no other gender differences.

Table 2 shows the means and standard deviations as a function of academic class. In general, the higher the class standing of the student, the lower the CDDA scores (the less the degree of problems). One-way ANOVAs with post hoc comparisons using Tukey tests showed that freshmen had significantly more problems with decision anxiety, $F(d f$ $=2,841)=7.39, p<.001$, and secondary gain motivations, $F(d f=2,841)$ $=15.86, p<.001$, than did sophomores or first-semester juniors (see Table 2). Their CDDA total scores were also significantly higher than were those of the other two groups, $F(d f=2,841)=5.73, p<.001$. No other differences were found as a function of academic class.

\section{Factor Analysis}

Bansberg and Sklare's (1986) factor analysis procedure of setting for a maximum number of five factors, oblique rotation, and minimum eigenvalue of 1.0 was followed. This type of exploratory factor analysis is preferable to the more complex methods of the confirmatory method for scale development research (Comrey, 1988; Tinsley \& Tinsley, 1987). The number of factors was set at five for several reasons. First, factor analysis should be a theory-driven process, not a statistics-driven process (Armstrong, 1967), and the five factors were already theoretically derived by Bansberg and Sklare (1986). Second, there was no compelling theory to suggest more than five factors. Third, strictness in setting the number of factors in a factor analysis procedure is recommended (Comrey, 1988). The rationale for using an oblique rotation was its appropriateness for constructs (i.e., subscales) that are correlated (Norusis, 1985).

The test used for measuring the appropriateness of the 34-item correlation matrix was the Kaiser-Meyer-Olkin (KMO) measure of sampling adequacy (Norusis, 1985). The KMO test produces a value between 0 and 1; a value above .60 suggests that a factor analysis is appropriate. The KMO value for the current data was .92, indicating that a factor analysis procedure was appropriate based on the interrcorrelation matrix of all items.
The percentage of variance explained by each CDDA subscale was as follows: DA explained the most variance (28.3\%); SG explained $8.2 \%$; AO, 6.3\%; LGA, 4.8\%; and LFO, 3.9\%. The total variance explained by the five subscales was $51.4 \%$.

The factor loadings of each item on the CDDA are presented in Table 3. An item was considered loaded on a factor if its loading was .30 or greater. All SG items loaded on the SG factor. All but two DA items loaded on the DA factor. All AO items loaded on the AO factor. All but one LGA item loaded on the LGA factor. An additional item loaded on both the LGA factor and the AO factor. All but two LFO items loaded on the LFO factor. In summary, $85 \%$ of the items loaded on their theoretically appropriate factors.

\section{Convergent Validity}

Evidence for convergent validity for the CDDA was assessed by comparing the students' scores on the CDDA to their scores on the CDS (Osipow, 1980). The Pearson product-moment correlation coefficient for the two measures was $r=.71, p<.05$. The correlations between the CDDA subscales and the CDS ranged from $r=.42$ to $r=.69$.

\section{Reliability}

The internal consistency reliability coefficient (Cronbach's alpha) for the CDDA total scale was .92 . The reliability coefficients for the subscales were as follows: LGA, .79; DA, .86; AO, .75; LFO, .75; and SG, .82. These results are almost identical to Bansberg and Sklare's (1986) findings.

\section{DISCUSSION}

A general answer to the question posed in this study (are Bansberg and Sklare's [1986] reliability and validity results replicable with a different

TABLE 2

Means, Standard Devlations, ANOVA, and Tukey Test Results for CDDA Subscale Scores for Academic Classes

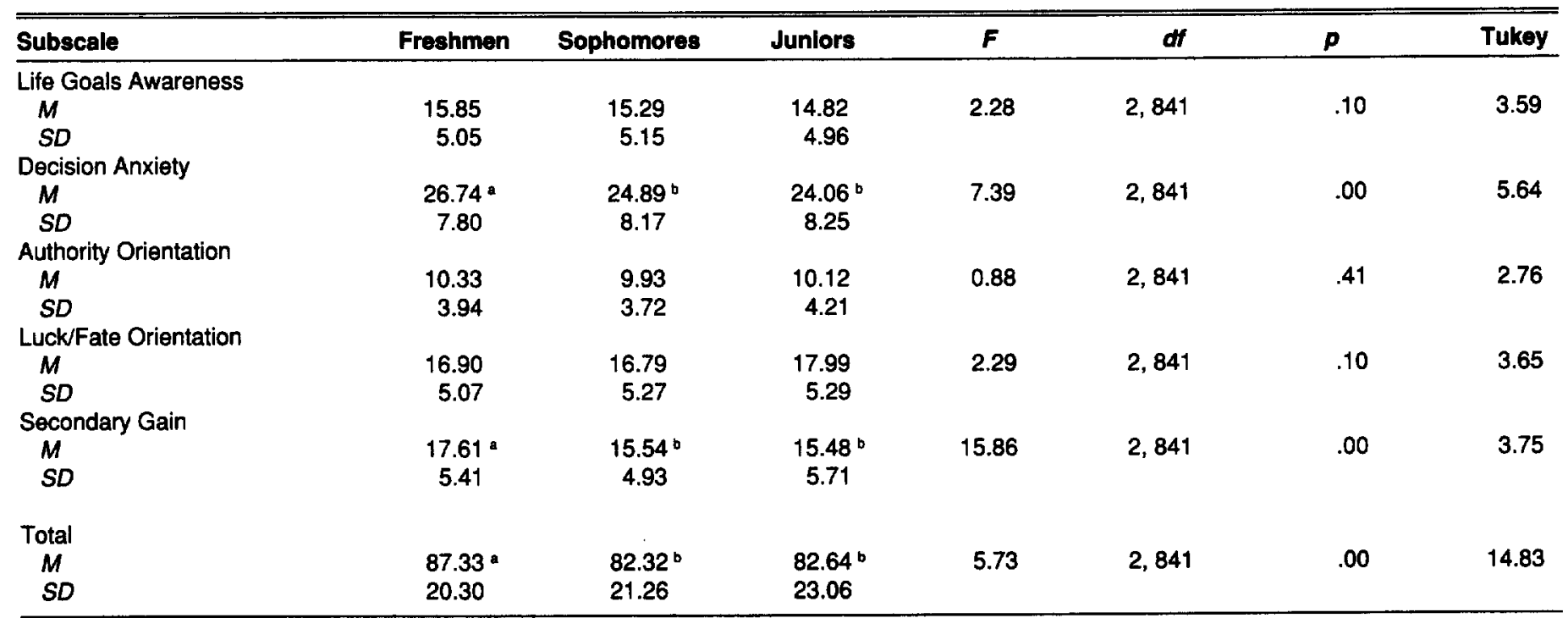

Note. See Table 1 Note for scale ranges and directions. $n$ (freshman) $=468 ; n$ (sophomores) $=267 ; n$ (juniors) $=109$.

Means with different superscripts are significantly different $(p<.05)$; those with the same or no superscripts are not significantly different. 
TABLE 3

Factor Loadings of Each Item of the CDDA for the Total Sample

\begin{tabular}{|c|c|c|c|c|c|c|}
\hline Item & Subscale & DA & SG & LFO & LGA & AO \\
\hline 3 & LGA & -.05 & -.14 & -.12 & .64 & -.11 \\
\hline 4 & LFO & .04 & .02 & .83 & -.08 & -.02 \\
\hline 5 & SG & .16 & -.62 & .02 & .04 & -.02 \\
\hline 6 & LGA & .28 & .26 & .08 & .37 & .16 \\
\hline 7 & $A O$ & .12 & .19 & .13 & -.05 & .60 \\
\hline 8 & $L^{\prime G A}$ & -.12 & .16 & .13 & -.21 & -.53 \\
\hline 9 & LFO & .09 & .08 & -.72 & -.04 & -.20 \\
\hline 10 & DA & -.51 & .17 & .04 & -.06 & -.19 \\
\hline 11 & DA & -.75 & .06 & .10 & -.10 & -.05 \\
\hline 12 & $A O$ & .04 & -.14 & .15 & -.08 & .43 \\
\hline 13 & LGA & -.21 & -.13 & .14 & .81 & .02 \\
\hline 14 & LFO & .08 & -.05 & .69 & .10 & -.05 \\
\hline 15 & SG & .10 & .65 & -.03 & -.07 & -.06 \\
\hline 16 & DA & -.66 & -.03 & -.03 & -.07 & -.12 \\
\hline 17 & $A O$ & -.01 & .03 & -.03 & -.01 & -.76 \\
\hline 18 & LGA & -.22 & -.02 & -.14 & -.67 & .10 \\
\hline 19 & LFO" & -.18 & .45 & -.25 & -.08 & .15 \\
\hline 20 & SG & -.27 & .52 & -.10 & -.12 & .04 \\
\hline 21 & DA & -.73 & .00 & .04 & -.22 & -.01 \\
\hline 22 & $A O$ & .03 & -.10 & .06 & .02 & .67 \\
\hline 23 & LFO & -.07 & .08 & .64 & .06 & .05 \\
\hline 24 & SG & -.11 & -.84 & -.09 & -.02 & -.12 \\
\hline 25 & DA & .66 & -.15 & .00 & -.00 & .07 \\
\hline 26 & $A O$ & -.01 & .16 & .06 & .04 & .70 \\
\hline 27 & DA & .76 & -.08 & -.04 & -.04 & .02 \\
\hline 28 & LFO $^{a}$ & .56 & -.01 & .25 & .05 & .00 \\
\hline 29 & SG & .01 & -.69 & .06 & .09 & .00 \\
\hline 30 & DA & .48 & .10 & .10 & .14 & .17 \\
\hline 31 & $\mathrm{LGA}^{\mathrm{a}}$ & .03 & .03 & -.10 & .37 & .45 \\
\hline 32 & LFO & .19 & -.25 & .36 & -.02 & .08 \\
\hline 33 & $\mathrm{DA}^{\mathrm{a}}$ & .28 & -.08 & .06 & .04 & .33 \\
\hline 34 & SG & .28 & -.65 & -.06 & -.01 & -.01 \\
\hline 35 & LGA & .15 & .05 & .02 & .74 & -.01 \\
\hline 36 & $\mathrm{DA}^{\mathrm{a}}$ & .09 & -.14 & -.02 & .06 & .46 \\
\hline
\end{tabular}

Note. $N=844 . D A=$ Decision Anxiety; $S G$ = Secondary Gain; $L F O=$ Luck and Fate Orientation; LGA = Life/Goal Awareness;AO = Authority Orientation.

a indicates loadings on "wrong" subscale or on more than one subscale.

sample?) is a qualified yes. Factor analysis showed that most of the CDDA items loaded on the same factors as in Bansberg and Sklare's original study. Five items failed to load on the predicted subscales: Items 36 and 33 (DA items), item 8 (an LGA item), and items 19 and 28 (LFO items). It seems easy to understand why item 36 may be a poor measure of anxiety. It reads "I have a fear of success." The other DA items deal more directly with decision anxiety (e.g., item 25: "In all honesty, I view career planning like going to the dentist. It is something that eventually has to be done but I would rather not think about it now"). Item 33 reads " On important decisions I find myself often not committing to one side or the other but staying in the middle." This item does not suggest that the person necessarily perceives this middle ground as anxiety producing.

It is more difficult to understand why item 8 did not load on the LGA subscale. This item reads "I don't know enough about myself in order to make a good career/job choice." This item appears to have face validity for the LGA subscale. Most of the other LGA items, however, deal with life goals and being able to have specific things a person needs in a career, whereas item 8 deals with " knowing oneself." Perhaps this item is too general and students struggled to interpret it. "Understanding one's goals, values, needs and interests" may be a better wording for such a better wording for such an item.

Item 19 reads " I don't worry about making a career decision because I am sure when the time is right the pieces will all fall together." The inclusion of the phrases "I don't worry" and "when the time is right" adds additional meaning to the item and may be the cause of it's not loading on the LFO factor. Item 28 reads "I tend to leave too much to luck/fate and as a result, don't aggressively plan for my future." This item seems to try to measure two concepts simultaneously: leaving too much to luck or fate and lack of planning. These two separate but related meanings may be responsible for the item's not loading on the LFO factor. Further factor analysis procedures with other samples are needed to validate that items $36,33,8,19$, and 28 are poor items and thus should be eliminated from the instrument.

Correlations between the CDDA total score and subscale scores and the CDS were calculated as a test of convergent validity. The results provide more evidence of convergent validity for the CDDA. The Pearson correlations between the CDS and the CDDA subscales were the following: $r=.57$ for LGA; $r=.69$ for DA; $r=.48$ for $\mathrm{AO} ; r=.42$ for LFO; $r=.49$ for SG; and $r=.71$ for the CDDA total score. All correlations were significant at the $p<.001$ level.

Preliminary norm scores for the CDDA were presented by gender, whereas Bansberg and Sklare (1986) did not report norm scores for the CDDA by gender. We report them for our sample. The results of this study are consistent with predictions that have been made concerning gender differences on the CDDA (see Larson et al., 1991, for a detailed discussion of gender and career decision problems). That is, women's unique career development process and the influences of socialization and psychological differences would predict that they would have more problems than men with life/goal awareness and authority orientation (Larson et al., 1991). These findings may be interpreted to support the validity of the CDDA. In both this study and Bansberg and Sklare's (1986) study, no significant differences were found between men and women on the CDDA total score. These findings indicate that men and women may not vary significantly in terms of the overall degree of career decision problems (i.e., total score), but may vary on the specific types of career decision problems (i.e., subscale scores). These results also support the findings of Hartman, Jenkins, Fuqua, and Sutherland (1987), who found qualitative gender differences on the Career Decision Scale (CDS). More research is needed to explain the psychological and socialization factors that are related to these gender differences on both the CDDA and the CDS.

This study also confirms the internal consistency reliability of the CDDA for a university student sample. The results were nearly identical to Bansberg and Sklare's (1986) study with high school and community college students. The reliability of the CDDA with other samples (e.g., young adults who are not students) is yet to be determined.

The results of this study provide substantial support for the reliability and validity of the CDDA when used with university students. Evidence from Bansberg and Sklare's (1986) study and this one suggests that the CDDA may provide the career counselor with valid and reliable information about some of the psychological causes of career indecision. It is not clear, however, what the factor structure would be for decided individuals. Further research is needed to determine if the CDDA can be reliably used with decided students, as Bansberg and Sklare claimed it can.

Although the CDDA is similar to the CDS, some of its constructs (i.e., subscales) are different. Although it seems that the two measures 
have substantial overlap in their measurement of an underlying construct, a potentially important advantage of the CDDA as compared with the CDS is the five subscales that can be used by the career counselor to differentially diagnose career decision problems. A frequently reported problem with instruments like the CDS is that it provides only a single total score (Slaney, 1988).

The preliminary norms provided in Tables 1 and 2 can be used by the career counselor in the assessment of career decision problems with university students until national norms can be established. Based on these findings, it is suggested that career counselors use scores that are one standard deviation above the mean or greater on each subscale as the cut-off scores for "high-range scores." For example, a score of 33 for men and 34 for women on the DA subscale would be considered a high score, whereas in the Bansberg and Sklare (1986) sample, a score of 30 for both sexes was considered high.

Future revisions of the CDDA should consider adding or subtracting items so that the number of items per subscale are the same. With equal numbers of items per subscale, direct comparisons could be made between the different scores on the subscales for an individual. In addition, having more items on a particular subscale inadvertently gives it more weight in the CDDA total score.

The CDDA seems only partially able to discriminate between individuals on the basis of academic class standing. That is, freshmen scored higher than did sophomores and juniors on the DA and SG subscales and on the CDDA total score. Although education and maturation may explain these academic class differences on the CDDA, more research is needed to explain why no significant differences were found on the other CDDA subscales.

The psychometric qualities of the CDDA as described in this study justify it as an instrument worthy of continued study by career counselors for further verification of its validity and reliability. The CDDA provides information about the psychological causes of career indecision that other instruments also provide (i.e., decision anxiety and life/goal awareness). The unique areas which the CDDA assesses include authority orientation, luck-and-fate orientation, and secondary gain motivation. The CDDA seems to have the potential of joining the ranks of the few valid and reliable assessment instruments for career decision problems.

\section{REFERENCES}

Armstrong, J. S. (1967). Derivation of theory by means of factor analyses, or Tom Swift and his electric factor analysis machine. American Statistician, 21 , $17-21$

Astin, A. S. (1984). The meaning of work in women's lives: A sociopsychological model of career choice and work behavior. The Counseling Psychologist, $12,117-126$

Bansberg, B., \& Sklare, J. (1986). The career decision diagnostic assessment. Monterey, CA: CTB/McGraw-Hill.

Comrey, A. L. (1988). Factor analytic methods of scale development in personality and clinical psychology. Journal of Counseling and Clinical Psychology $56,754-761$.

Crites, J. (1981). Career counseling models, methods, and materials. New York: McGraw-Hill.

Dollard, J., \& Miller, N. E. (1950). Personality and psychotherapy. New York: McGraw-Hill.
Esposito, R. P. (1977). The relationship between the motive to avoid success and vocational choice. Journal of Vocational Behavior, 21, 29-34.

Fitzgerald, L. F., \& Betz, N. E. (1983). Issues in the vocational psychology of women. In W. B. Walsh \& S. H. Osipow (Eds.), Handbook of vocational psychology (pp. 83-159). Hillsdale, NJ: Erlbaum.

Frankl, V. E. (1970). The will to meaning: Foundations \& applications of logotherapy. New York: New American Library.

Haase, R. F. (1980). Experiment wise error rate protection in multi-variable univariate analysis. Duplicated manuscript, State University of New York at Albany.

Haase, R. F., \& Ellis, M. V. (1987). Multivariate analysis of variance. Journal of Counseling Psychology, 34, 404-413.

Hartman, B. W., Fuqua, D. R., \& Blum, C. R. (1985). A path-analytic model of career indecision. Career Development Quarterly, 33, 231-240.

Hartman, B. W., Jenkins, S. J., Fuqua, D. R., \& Sutherland, V. E. (1987). An analysis of gender differences in the factor structure of the Career Decision Scale. Educational and Psychological Measurement, 47, 1099-1 106.

Holland, J. L., \& Holland, J. E. (1977). Vocational indecision: More evidence and speculation. Journal of Counseling Psychology, 24, 404-414.

Kapes, J. T., \& Mastie, M. M. (1988). A counselor's guide to career assessment instruments. Alexandria, VA: National Career Development Association.

Krumboltz, J. D., \& Thoresen, C. E. (1976). Counseling methods. New York: Holt, Rinehart, \& Winston.

Larson, J. H., Butler, M., Wilson, S., Medora, N., \& Allgood, S. (1991). The effects of gender on career decision problems in young adults. Paper submitted for publication.

Norusis, M. J. (1985). Advanced statistics guide: SPSS-X. New York: McGrawHill.

Oliver, L. W. (1979). Overcome measurement in career counseling research. Journal of Counseling Psychology, 26, 217-226.

Osipow, S. H. (1980). Manual for the career decision scale. Columbus, $\mathrm{OH}$ : Marathon Consulting Press.

Osipow, S. H. (1983). Theories of career development. New York: Prentice-Hall. Perls, F. S. (1979). Planned psychotherapy. Gestalt Journal, 2, 5-23.

Rotter, J. B. (1954). Social learning and clinical psychology. Englewood Cliffs, $\mathrm{NJ}$ : Prentice-Hall.

Slaney, R. B. (1980). Expressed vocational choice and vocational indecision. Journal of Counseling Psychology, 27, 122-129.

Slaney, R. B. (1988a). The assessment of career decision making. In W. B. Walsh \& S. H. Osipow (Eds.), Career decision making (pp. 33-76). Hillsdale, NJ: Erlbaum.

Taylor, K. M. (1982). An investigation of vocational indecision in college students: Correlates and moderators. Journal of Counseling Psychology, 34, 414-424.

Tinsley, H. E., \& Tinsley, D. J. (1987). Use of factor analysis in counseling psychology research. Journal of Counseling Psychology, 34, 414-424.

Zytowski, D. G., \& Betz, E. L. (1972). Measurement in counseling research: A review. Counseling Psychologist, 1, 72-86.

Jeffry H. Larson is an associate professor in the Department of Family Sciences at Brigham Young University, Provo, Utah. Dean M. Busby is an assistant professor in the Department of Child, Family, and Consumer Studies at Syracuse University, Syracuse, New York. Stephan Wilson is an associate professor in the Department of Family Studies at the University of Kentucky, Lexington. Nilufer Medora is an associate professor in the Department of Home Economics at California State University-Long Beach. Scot Allgood is an assistant professor in the Department of Family and Human Development at Utah State University, Logan. Preparation of this article was supported in part by a grant from the Women's Research Institute, Brigham Young University, Provo, UT. Correspondence regarding this article should be sent to Jeffry H. Larson, Department of Family Sciences, Brigham Young University, Provo, UT 84602. 